\title{
Síndrome de Plummer-Vinson: relato de caso
}

\section{Plummer-Vinson syndrome: a case report}

\author{
Iana Silva Dias"; Francisco Assis Costa²; Alana Costa Borges33; Edenilce Evangelista Correia ${ }^{4}$; Márcio Falcão Macedo ${ }^{5}$
}

INTRODUÇÃO

A síndrome de Plummer-Vinson (SPV), também conhecida como síndrome de Paterson-Kelly ou disfagia sideropênica, é conhecida pela presença da tríade clássica de disfagia cervical, anemia ferropriva e membrana no esôfago superior $^{1}=$ associada glossite atrófica e queilite angular .

É uma doença rara, sendo difícil determinar sua prevalência, já que na literatura médica são publicados apenas relatos de caso. É mais comum em mulheres de meia idade².

É considerada fator de risco para o desenvolvimento de carcinoma de células escamosas de faringe e esôfago ${ }^{2}$, e também existem alguns relatos de sua associação com câncer gástrico ${ }^{3}$.

Neste artigo, os autores apresentam o caso de uma paciente diagnosticada com síndrome de PlummerVinson há aproximadamente um ano.

\section{RELATO DO CASO}

Paciente do sexo feminino, 38 anos de idade, branca, queixando-se de disfagia cervical, para sólidos, há vários anos. Em 2001, realizou uma endoscopia digestiva alta que evidenciou espasticidade de esfíncter esofagiano superior. Um ano após, foi submetida a um esofagograma (Figura 1) que revelou imagem estenosante do esôfago ao nível do introito torácico determinando discreto retardo no trânsito do contraste.

Após tratamento da estenose com dilatação pela sonda de Savary, houve uma melhora temporária. Entretanto, endoscopia de controle, dois meses depois, mostrou que uma nova nova membrana se formara ao nível do músculo cricofaríngeo e a disfagia progrediu para líquidos.

Nos anos seguintes, foi submetida à quatro dilatações, com alívio apenas temporário dos sintomas e perda ponderal de seis quilos.

$\mathrm{Na}$ história pregressa havia relato de anemia, tratada irregularmente com "ferro oral" por conta própria. Referia também adinamia de longa data e alguns episódios de taquicardia. Negava alterações menstruais e fezes escuras.
Ao exame físico, apresentava sinais de anemia crônica (Figura 2), como queilite angular, glossite e coiloníquia. Exames laboratoriais evidenciaram importante anemia ferropriva, quando foi diagnosticada SPV.

Anticorpos marcadores de doença celíaca (antiendomísio e antigliadina) foram pesquisados, apesar da falta de clínica, e foram negativos. A provável etiologia de sua anemia era carencial. Exames de função tireoideana foram normais.

A paciente foi tratada com sulfato ferroso oral por três meses e está assintomática, atualmente em acompanhamento ambulatorial. Seus últimos exames mostram testes hematimétricos e estoques de ferro normais.

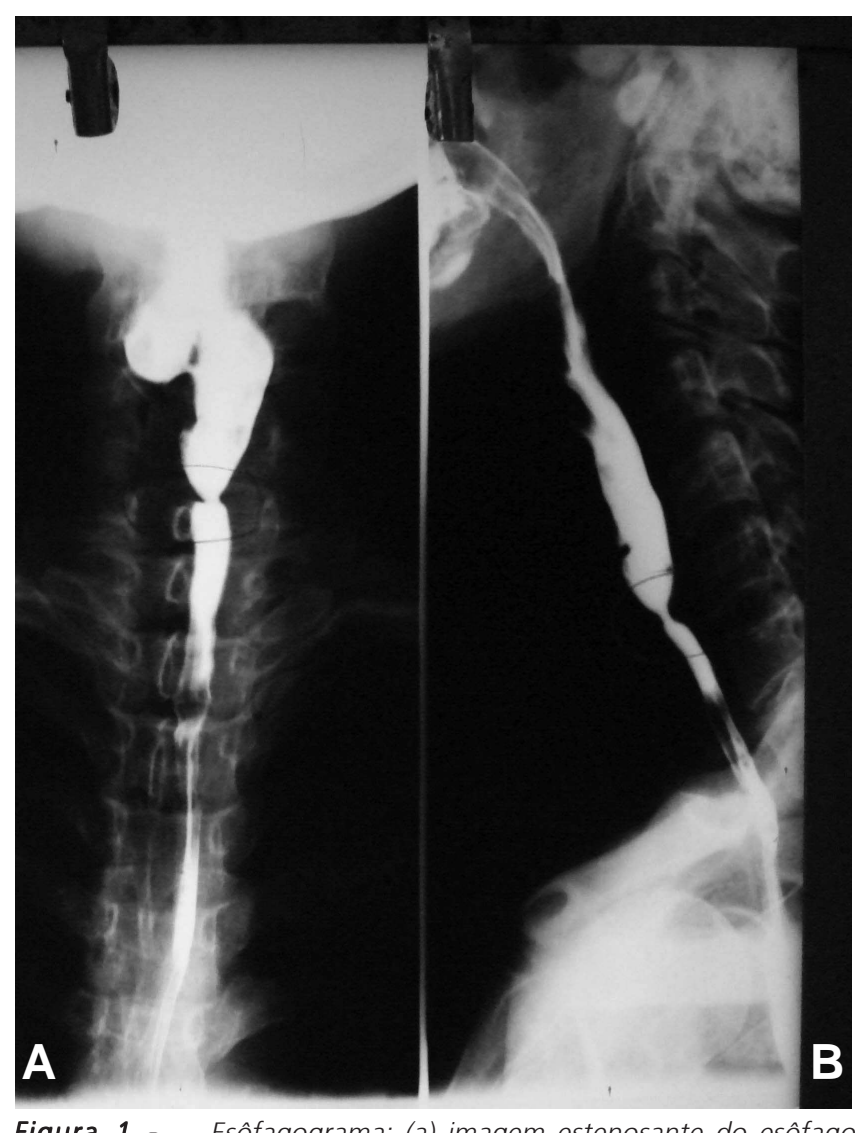

Figura 1 - Esôfagograma: (a) imagem estenosante do esôfago ao nível do intróito torácico e (b) discreto retardo no trânsito do contraste.

Trabalho realizado no Serviço de Cirurgia Geral do Hospital Geral de Fortaleza - CE.

1. Médica Cirurgiã Plástica e Preceptora do Serviço de Cirurgia Plástica e Microcirurgia Reconstrutiva da Universidade Federal do Ceará-CE-BR;

2. Médico Cirurgião Geral e Preceptor do Serviço de Cirurgia Geral do Hospital Geral de Fortaleza; 3. Médica Cirurgiã Geral do Hospital Municipal Edmilson Barros de Oliveira; 4. Médica Endoscopista Digestiva e Preceptora do Serviço de Endoscopia Digestiva da Emergência do Hospital Geral de Fortaleza; 5. Médico Cirurgião Geral do Hospital Municipal Edmilson Barros de Oliveira reside. 


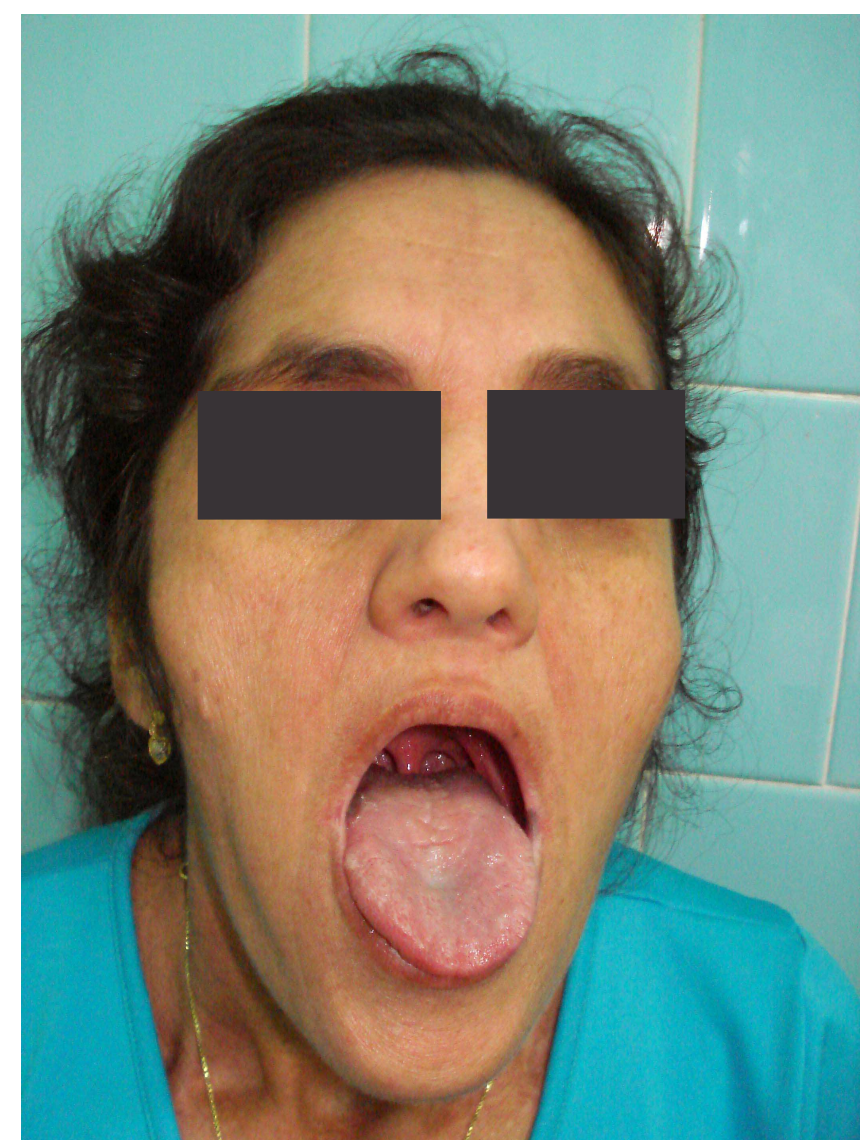

Figura 2 - Sinais de anemia crônica: queilite angular, glossite.

\section{DISCUSSÃO}

A associação de disfagia, anemia ferropriva e a presença de uma membrana em esôfago superior caracte- rizam a SPV. Geralmente ocorre em mulheres brancas entre 40 e 70 anos de idade, como no presente caso, embora haja relatos da síndrome em crianças².

A disfagia usualmente não é acompanhada de odinofagia, e pode ser intermitente ou progressiva ao longo dos anos, limitada aos sólidos e, ocasionalmente, associada à perda de peso. Os sintomas da anemia ferropriva como palidez, fadiga e taquicardia podem predominar no quadro clínico ${ }^{1,4}$.

As membranas esofágicas são finas e horizontais, por vezes mais de uma. Usualmente são protusões da parede anterior, com extensão lateral, poupando a parede posterior. Assim, raramente ocupam toda a circunferência esofágica. Como são finas, podem não ser percebidas ou serem rompidas acidentalmente, a não ser que o endoscópio seja introduzido por visualização direta ${ }^{3}$.

A patogênese da doença é incerta. O fator etiológico mais importante é a deficiência de ferro. Outros fatores incluem predisposição genética e doenças autoimunes: doença celíaca (a mais frequente), tireoidite e artrite reumatoide ${ }^{2}$. Neste caso, estas doenças foram descartadas.

A SPV pode ser tratada efetivamente por meio de suplementação de ferro e dilatações endoscópicas. Em muitos casos, apenas a reposição de ferro pode resolver. Todavia, em casos de obstrução significativa do lúmen esofágico, a dilatação impõe-se ${ }^{4}$.

Usualmente uma sessão de dilatação é suficiente para alívio dos sintomas, mas, ocasionalmente, são requeridas múltiplas sessões, como no presente caso. Controle endoscópico anual é necessário, visto que a doença é considerada fator de risco para neoplasias de faringe e esôfago ${ }^{2,4}$.

\section{A B S T R A C T}

We present a case of Plummer-Vinson syndrome, which is a rare condition nowadays. The diagnosis was made after years of the disease, many doctors having attended the patient. The treatment consisted of oral supplementation of iron and endoscopic dilatations. The patient is asymptomatic.

Key words: Anemia. Anemia, iron-deficiency. Deglutition disorders. Esophagus. Plummer-Vinson, syndrome.

\section{REFERENNCIAS}

1. Demirci $F$, Sava ${ }^{\circ}$ MC, Kepkep N, Okan V, Yilmaz M, Büyükberber $M$, et al. Plummer-Vinson syndrome and dilation therapy: a report of two cases. Turk J Gastroenterol. 2005;16(4):224-7.

2. Novacek G. Plummer-Vinson syndrome. Orphanet J Rare Dis. 2006;1:36.

3. Kim KH, Kim MC, Jung GJ. Gastric cancer occurring in a patient with Plummer-Vinson syndrome: a case report. World J Gastroenterol. 2005;11(44):7048-50.

4. Gregório CL, Barros EL, Koshimura ET, Violato RF, Sá VHLC, Betti $E$, et al. Disfagia sideropênica (síndrome de Plummer-Vinson ou Paterson-Kelly): relato de caso e revisão de literatura. Arq med ABC. 2005;30(2):103-5.
Recebido em 02/05/2007

Aceito para publicação em 03/06/2007

Conflito de interesse: nenhum

Fonte de financiamento: nenhuma

\section{Como citar este artigo:}

DIAS IS, COSTA FA, BORGES AC, CORREIA EE, MACEDO MF. Síndrome de Plummer-Vinson: relato de caso. Rev Col Bras Cir. [periódico na Internet] 2013;40(1). Disponível em URL: http://www.scielo.br/rcbc

\section{Endereço para correspondência:}

Edenilce Evangelista Correia

E-mail: edenilceec@globo.com 